\title{
A systematic review of the approaches to multi- level learning in the general practice context, using a realist synthesis approach: BEME Guide No. 55
}

\author{
Marie-Louise Dick, Margaret Henderson, Yi Wei, David King, Katrina \\ Anderson \& Jill Thistlethwaite
}

To cite this article: Marie-Louise Dick, Margaret Henderson, Yi Wei, David King, Katrina Anderson \& Jill Thistlethwaite (2019) A systematic review of the approaches to multi-level learning in the general practice context, using a realist synthesis approach: BEME Guide No. 55, Medical Teacher, 41:8, 862-876, DOI: 10.1080/0142159X.2019.1595554

To link to this article: https://doi.org/10.1080/0142159X.2019.1595554

View supplementary material ¿

Published online: 23 Apr 2019.

Submit your article to this journal 주

Lll Article views: 362

Q View related articles ¿ك

View Crossmark data $₫$ 


\title{
A systematic review of the approaches to multi-level learning in the general practice context, using a realist synthesis approach: BEME Guide No. 55
}

\author{
Marie-Louise Dick ${ }^{\mathrm{a}}$, Margaret Henderson ${ }^{\mathrm{a}}, \mathrm{Yi} \mathrm{Wei}^{\mathrm{a}}{ }$ David King $^{\mathrm{a}}$, Katrina Anderson ${ }^{\mathrm{b}}$ and Jill Thistlethwaite ${ }^{\mathrm{c}}$

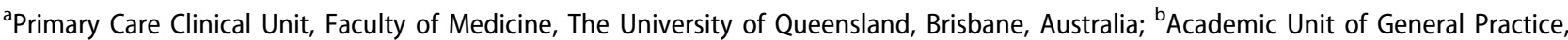 \\ Australian National University Medical School, Canberra, Australia; ${ }^{C}$ Faculty of Arts and Social Sciences, University of Technology \\ Sydney, Australia
}

\begin{abstract}
Background: Recent global increases in medical student numbers and shifts in medical education from teaching hospitals to community settings call for effective strategies to meet the demand for general practice teaching placements. It has been proposed that "multi-level learning" (MLL), in which learning and teaching are shared across different levels of learners, may provide teaching efficiencies and valuable experiences for learners and teachers.

Aims: To identify, evaluate and synthesize the evidence related to the types, benefits, challenges, and facilitators of MLL in community-based general practice, and the underlying mechanisms and associated contexts to explain the reported outcomes.

Method: A realist synthesis approach guided the systematic review.

Results: Fifteen papers were identified, providing primary evaluation data predominantly from interviews with or surveys of key stakeholders. Generally, all levels of learners reported overall satisfaction with their MLL experiences. Medical students appreciated learning from prevocational doctors and registrars due to social and cognitive congruence. Mechanisms and contexts that supported our hypotheses regarding successful MLL outcomes were identified, with "a strong teaching culture" being a major mechanism.

Conclusions: The findings can help inform practices considering the implementation or enhancement of MLL initiatives in general practice. Further research should include measuring defined learning outcomes.
\end{abstract}

\section{Introduction}

Globally, medical student numbers have increased substantially in recent decades. In the United Kingdom (UK), numbers increased 62\% from 1999/2000 to 2010/2011 (The Health and Education National Strategic Exchange 2012) and 95\% in Australia from 2003 to 2012 (Health Workforce Australia 2014), with projected increases in the United States of America (USA) expected to be met three years ahead of schedule (Broder 2013). A flow-on effect is increased numbers of medical graduates undertaking postgraduate specialty training. Additionally, medical education has shifted from being predominantly hospital-based to having a greater representation in community settings, as advocated in the 1988 Edinburgh Declaration (World Federation for Medical Education 1988). This trend is affecting many regions including the UK (Park et al. 2015) and the USA (Association of American Medical Colleges 2016).

The requirement for medical students and doctors undergoing postgraduate specialist training to have workbased training and supervision in clinical settings, along with the economic pressures for shorter in-patient stays and early hospital discharge (Sen Gupta and Spencer 2001) supports the need for educational supervision in community settings.

In Australia, general practice is defined as a specialty that provides "person-centred, continuing, comprehensive

\section{Practice points}

- Multi-level learning (MLL) is the sharing of teaching and learning across different levels of learners.

- Benefits of MLL over non-MLL teaching approaches in general practice may include a broader range of learning opportunities, and time and cost efficiencies for some practices.

- A strong teaching and learning culture, social and cognitive congruence and flexible teaching methods are considered important underlying mechanisms.

and coordinated whole person healthcare to individuals and families in their communities" (RACGP 2011, p. xi). General practitioners (GPs) are the primary medical specialist delivering this care. Other terms such as "family medical practitioner," "family physician," and "family doctor" are used to describe primary care medical practitioners globally (RACGP 2011). For the purpose of this review, we use GP to incorporate all these terms.

GPs are integral in the supervision and training of medical learners at various stages of their professional development including students, prevocational doctors (qualified doctors in clinical training who are undertaking supervised

CONTACT David King d.king@uq.edu.au P Primary Care Clinical Unit, Faculty of Medicine, The University of Queensland, Level 8, Health Sciences Building, Royal Brisbane and Women's Hospital Complex, Herston Road, Herston, Brisbane, Queensland, Australia.

(4) Supplemental data for this article can be accessed here. 
work, but who have not yet enrolled in a vocational specialty training program (RACGP 2011)), and registrars (medical practitioners undertaking specialty vocational training) (Supplementary Appendix 1 Glossary of terms). General practice placements provide learners with valuable exposure to community-based medicine, yet also increase demand on GPs to provide supervision and teaching. Effective strategies are clearly needed to meet the increasing demand for general practice teaching capacity without overburdening already busy GPs.

Shared teaching and learning across all medical learner stages is one proposed strategy. This approach has been referred to as multi-level learning (MLL) (Morrison et al. 2014) and also as a vertical component of learning or vertical integration (Supplementary Appendix 1 Glossary of Terms) in medical education (Dick et al. 2007; Hays 2013; O'Regan et al. 2013; GPSA 2014; Thomson et al. 2014). For this report, we use the term MLL to refer to shared teaching and learning that occurs between the four stages of general practice training, i.e. medical students, prevocational doctors, registrars, and GP supervisors, such that different levels of learners learn together. It includes teaching from learners to one or more other learners who are on a different level of medical education training (e.g. a registrar teaching a medical student or a prevocational doctor). It also incorporates a GP concurrently teaching two or more learner levels, e.g. medical students, prevocational doctors, and registrars.

Hospital-based registrars have for many years assisted their specialist supervisors in teaching medical students and prevocational doctors, with benefits for both students, and registrar equivalents when teaching skills courses have been provided (Busari and Scherpbier 2004; Bensinger et al. 2005). However, this MLL approach has not been usual practice in community-based practices, where GPs have traditionally provided most or all of the training to medical learners.

More recently, the use of MLL in general practice has been increasing. Stocks et al. (2011) reported that 11 out of $17(65 \%)$ Australian general practice regional training providers (responsible for delivering vocational training for GP registrars) had developed some vertical integration initiatives. These included registrars teaching prevocational doctors and medical students, GP supervisors running multi-level educational sessions, and the provision of basic teaching skills training for GP registrars (Stocks et al. 2011). In England, two independent surveys of GP registrars found that $62 \%$ were involved in some form of teaching - primarily focusing on medical students, but also other junior colleagues (Halestrap and Leeder 2011; Williams and Amiel 2012). The importance of registrars developing educational skills and involvement in teaching is recognized by many registrar/resident training bodies (RACGP 2011; General Medical Council 2013; Frank et al. 2015).

It has been proposed that MLL approaches in community-based general practices could assist in delivering education to learners by reducing the educational burden on already-busy GPs (Dick et al. 2007; Anderson and Thomson 2009) while increasing the capacity for community-based learner supervision, and providing a variety of experiences for teachers and learners (Dick et al. 2007).
Existing literature reviews provide valuable perspectives on aspects of MLL in general practice, including its benefits and challenges (O'Regan et al. 2013); the role of registrars as teachers (Rushforth et al. 2010); and an overview of vertical integration of learning and teaching and how it can be developed, delivered, and adapted to various contexts (GPET 2011). These reviews provide an overview of articles hypothesizing about various aspects of MLL, with some referring to a small number of studies with primary evaluation data on the experience of MLL.

This Best Evidence Medical Education (BEME) review adds to the literature by using a formal systematic review methodology to identify and evaluate empirical primary research studies with evaluation data to (a) answer the following review questions:

1. What approaches to MLL and teaching have been used in the general practice context?

2. What are the reported benefits and disadvantages/ challenges of these approaches for each of the participant groups (e.g. for medical students, prevocational doctors, general practice registrars, GP supervisors, patients, and general practice administration staff)?

3. What factors are reported facilitators for the MLL approach?

and (b) identify mechanisms and their associated contexts to explain the reported outcomes.

\section{Methods}

We adopted a realist synthesis approach to guide the methodology for this review. This is the application of realist methods to secondary research, whereby a realist evaluation "seeks to establish what works, for whom, in what circumstances, in what respect, to what extent, and why" (Wong et al. 2012, p. 89), by identifying mechanisms (M), contexts $(\mathrm{C})$, and outcomes $(\mathrm{O})$ through the development and testing of hypotheses (Pawson and Tilley 1997). A realist synthesis (also known as a realist review):

applies realist philosophy to the synthesis of findings from primary studies that have a bearing on a single research question. It uses interpretive cross-case comparison to understand and explain how and why observed outcomes have occurred in the studies included in a review. (Wong et al. 2012, p. 93)

It is considered an approach particularly suited to education research (Wong et al. 2013). It "seeks to unpack the context - mechanism - outcome relationship, thereby explaining examples of success, failure and various eventualities in between" (Wong et al. 2013, p. 2).

In undertaking our systematic review, we were guided by key steps to be undertaken in a realist review (Pawson et al. 2005).

\section{Step 1: Clarify scope}

A scoping search of electronic databases supported the development of the review protocol. This, and the team's knowledge and experience of MLL, guided the study research questions and hypotheses/theories to inform the realist review (Box 1). 
Box 1 . Hypotheses/theories to inform the realist review

1. Multi-level learning is facilitated through the use of a range of approaches including methods and experiences.

2. Multi-level teaching and its facilitation between learners in adjacent/nearby levels of learning are effective because of the similar experiences of the learner-teachers and learners.

3. Multi-level learning approaches enhance the acquisition of teaching skills by participants.

4. Multi-level learning approaches facilitate time efficiencies for GP supervisors by sharing the teaching and learning roles amongst learner levels.

5. Multi-level learning approaches contribute positively to increase teaching capacity in the community by sharing the teaching and learning load amongst increased numbers of medical learners in the practice.

6. Multi-level learning fosters enthusiasm for general practice amongst medical students, prevocational doctors, and registrars.

\section{Step 2: Search for evidence}

Selection (inclusion and exclusion) criteria were developed (Table 1). Focusing on MLL as previously defined, we excluded studies looking only at: the traditional model of supervisor teaching one or more learners from the same level of learning; peer-learning (defined as "the acquisition of knowledge and skill through active helping and supporting among status equals or matched companions" (Topping 2005, p. 631)); or near-peer learning (involving the teaching and learning from "a trainee who is one or more years senior to another trainee on the same level of medical education training"(Bulte et al. 2007, p. 583)). As these latter two terms have been used interchangeably in the published literature, and the term near-peer has also been used to describe teaching of medical students by junior doctors (Rodrigues et al. 2009), our search strategy included these terms to minimize the risk of missing relevant articles.

Evaluation data from practices hosting more than one level of learner were included when it was evident that MLL teaching approaches were adopted by all or most of the study practices/participants. Evaluation data describing perceptions of staff from practices when it was unclear who had and who had not actively experienced MLL were not included.

Further exploratory literature searching allowed for refinement and finalization of the selection criteria and the search strategy (Supplementary Appendix 2).

\section{Searching the literature}

Electronic databases. In November 2015, six electronic databases PubMed, the Cumulative Index to Nursing and Allied Health Literature (CINAHL), Embase, Web of Science, Education Resources Information Centre (ERIC), and the Australian Educational Index (AEI) were searched using terms relating to general/family practice and MLL or teaching. The search syntaxes were developed in collaboration with a university librarian and modified for selected databases. Each database was searched in its entirety from earliest records to the date of the search. Updated searches of these databases were undertaken in July 2017 using the same search syntaxes. Where possible the repeat searches were checked by date-limiting the databases from November 2015 to 2017.

The titles and abstracts of identified references were independently reviewed by two topic review group (TRG) members to identify records that met/possibly met selection criteria. Differences in opinion were resolved by consensus of both members, or seeking and accepting a third member's opinion. Where no abstract was available the full publication was retrieved to determine inclusion suitability.

A total of 91 articles proceeded to the next level of screening, where full articles were assessed against selection criteria, using the reviewer process above. Fifteen articles were preliminarily deemed eligible for inclusion (Figure 1).

\section{Other sources}

- Article titles published in three journals from July 2007 to July 2017 inclusive were hand searched by a different TRG member for each journal. The journals Education in Primary Care, BMC Medical Education, and Australian Family Physician were selected because each had published several articles relevant to this review.

- One TRG member undertook internet searches seeking relevant key policy documents and grey literature.

- Reference lists of all articles preliminarily deemed eligible were hand searched for further relevant articles.

- Scopus was used to identify relevant publications citing the final selected group of articles. When no citations for a given reference were found, Web of Science was also searched.

Potentially relevant articles from these "other sources" were assessed similarly to articles found in the database searches. Eight further papers/reports were identified, resulting in 23 articles in total (Figure 1).

\section{Step 3: Appraise primary studies and extract data}

LineGuide ( ${ }^{(}$Network Playground 2015), a customizable online software program to assist the development of systematic reviews of medical research and clinical guidelines, was utilized to support the screening of references and assessment of selection criteria, and to document the critical appraisals and data extractions of included articles.

An initial inter-rater agreement exercise was conducted on two articles (independently assessed by five TRG

Table 1. Study inclusion and exclusion criteria.

- Studies that report approaches to MLL principally implemented in the general practice setting (some components may also be implemented in hospital/other community-based settings)

- Participants must include GP supervisors and at least two other learner levels (e.g. GP registrars and medical students) or at least two learner levels (not including GP supervisors)

- Studies that have evaluation data relating to the process/outcomes/ benefits of the multi-level learning initiative

- Studies that only focus on the traditional "GP supervisor as a teacher" models

- Studies with no evaluation data, including commentaries or opinion pieces without empirical data

- Studies not published in English

- Abstracts or conference PowerPoint presentations without associated full paper publications 


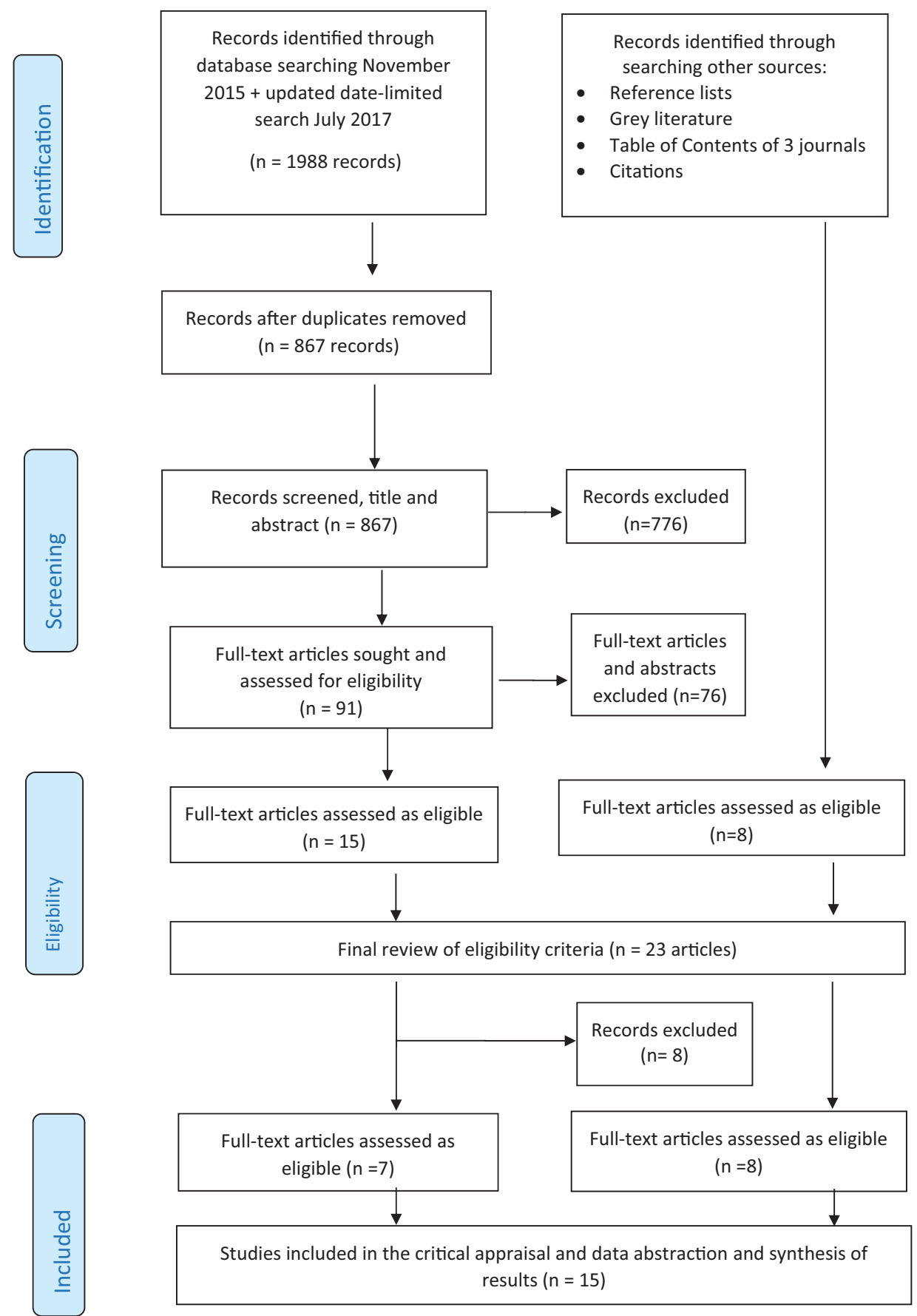

Figure 1. Flowchart for literature searching.

members), in an attempt to standardize assessments of selection criteria, quality appraisals, and data extractions.

All 23 articles were reviewed independently by two reviewers. TRG members did not review any papers they coauthored. A final check of each article against selection criteria resulted in eight ineligible articles for the following reasons: not clearly containing primary evaluation data; focusing on "near-peer" learning (as previously defined) rather than "multi-level" learning; and not reporting evaluation data separately for those with and without MLL experience (Figure 1).

The remaining 15 articles were appraised using the Critical Appraisal Skills Programme (CASP) Qualitative Research checklist for qualitative studies (Critical Appraisal Skills Programme 2018) and the cross-sectional/survey/ prevalence/observational study appraisal tool which includes common assessments of internal validity similar to those used in cross-sectional assessment tools such as the National Institute of Health (NIH) tool (National Institute of Health 2014). Given that consensus on the best method for critical appraisal of mixed method primary research studies is lacking (Heyvaert et al. 2013), we chose to appraise studies reporting mixed methods using both of the abovementioned tools, when both the quantitative and qualitative data from such studies were substantially relevant to our review questions. When mixed methods study data relevant to our review were entirely or predominantly either qualitative or quantitative, then the appraisal tool for that predominant study type was used. As per the proposed approach to a realist review (Pawson et al. 2005), judgment was used to supplement these formal critical appraisal checklists to consider both the relevance and rigor of each study.

Data extraction for each paper was undertaken by a first reviewer, using fields provided on LineGuide for the 
relevant study type (Supplementary Appendix 3). A second TRG member examined that reviewer's data extraction, suggested edits, and agreement was reached.

\section{Step 4: Synthesize evidence and draw conclusions}

Two TRG members (MH, DK) independently assessed the 15 included articles for data to answer the study's three key review questions. Reported teaching methods were tabulated (Question 1). Primary evaluation data relevant to the benefits, disadvantages/challenges, and facilitators for MLL (Questions 2 and 3) were collated and grouped under broad headings that were compared and agreed. Following review and feedback by three other team members, relevant evaluation data were further summarized independently (by TRG members MH and MLD). Key sub-headings were compared and agreed. A further review of the articles checked for data relevant to these subheadings.

Basing our analysis and synthesis process on that proposed by Wong et al. (2013), two TRG members (MH and MLD) independently reviewed each article to identify data that generated explanations for causation, i.e. an outcome (O) of interest was generated by relevant mechanisms (M) being triggered by one or more contexts (C). Findings were compared and discussed and articles reviewed again until consensus was reached. The remaining TRG members provided feedback on these contexts, mechanisms, and outcomes.

\section{Results}

We present the review findings under the following headings:

1. Search results

2. Critical appraisal and quality of evidence

3. Types of teaching

4. Benefits, disadvantages/challenges, and facilitating factors

5. Realist synthesis

\section{Search results}

Figure 1 displays the flow chart for the literature search.

Detailed characteristics of the 15 included papers that report data from 10 different research studies across two countries (Australia and England) are provided in Supplementary Appendix 4. Five of the Australian papers come from one research group in northern New South Wales; three of their papers relate to one research study (Ahern et al. 2013; Silberberg et al. 2013; van de Mortel et al. 2013) and two relate to a national survey (van de Mortel et al. 2014; van de Mortel et al. 2016). Two further Australian papers report data from one research study in Victoria (Morrison et al. 2014; Brown et al. 2015) and two English papers report different aspects of a research study in Yorkshire and Humber (Nagel et al. 2011; Kirby et al. 2014). The oldest paper, an exploratory pilot study, was published in 2003 (Johnson et al. 2003) indicating the relative infancy of MLL in the primary care setting.

Several studies used qualitative methods only: semistructured interviews (Ahern et al. 2013; Silberberg et al.
2013; van de Mortel et al. 2013; Kleinitz et al. 2014; Morrison et al. 2014; Thomson et al. 2014; Brown et al. 2015) or interviews and case reports (Harris 2009)). Others used mixed methods: a survey and semi-structured interviews (Gaby et al. 2014; Kirby et al. 2014); a survey and focus group discussions (Johnson et al. 2003); or a survey collecting predominantly quantitative data, with some qualitative free text responses (Williams and Amiel 2012; van de Mortel et al. 2014; van de Mortel et al. 2016). A postal questionnaire collecting only quantitative data was reported in one study (Nagel et al. 2011).

Study aims were diverse. One study investigated the benefits and challenges of teaching mental health using a MLL format (Gaby et al. 2014), while the two English papers (Nagel et al. 2011; Kirby et al. 2014) focused on determining the extent of junior doctor and GP trainee involvement in teaching and attitudes to such a role. Most Australian papers looked at the experiences of multiple stakeholders using MLL teaching and learning in the general practice setting. Only two papers from one study (Morrison et al. 2014; Brown et al. 2015) asked patients as stakeholders about their perceptions of MLL.

All evaluation data from five of the papers were eligible for inclusion (Ahern et al. 2013; van de Mortel et al. 2013; Kleinitz et al. 2014; Morrison et al. 2014; Thomson et al. 2014). Given the diversity of study aims, study participants, and presentation of study results, this was not the case for the remaining papers (Supplementary Appendix 4).

\section{Critical appraisal and quality of evidence}

The papers were critically appraised using the aforementioned appraisal tools and methods (Supplementary Appendix 5 Critical appraisal assessments). We considered the 13 peer-reviewed journal published articles were overall methodologically sound (satisfying most/all of the appraisal criteria). The criterion of reflexivity was variably addressed with some papers noting the potential for bias given the known relationship between researchers/interviewers and participants, others indicating the independent nature of their interviewer, and others not commenting on this.

The two non-peer reviewed reports were variably presented (Johnson et al. 2003; Harris 2009). Neither made reference to ethics committee approval. Johnson et al. (2003) provided reasonable detail about their pilot project and how it was evaluated. The project report by Harris (2009) lacked detailed descriptions of the methods and analysis and was not clearly structured. Despite this, we elected to retain it as we considered the data from its three case studies were relevant to this review.

\section{Types of teaching approaches}

A wide variety of teaching methods used within the MLL approach are described in the papers (Table 2).

\section{Benefits, disadvantages/challenges, and facilitating factors}

The key benefits and disadvantages/challenges of MLL approaches, as reported for learners, learner-teachers 
Table 2. Practice-based teaching approaches used in MLL practices.

\begin{tabular}{|c|c|c|}
\hline Teaching approaches & & References \\
\hline \multirow[t]{3}{*}{ Learner-teacher clinical supervision of juniors } & $\begin{array}{l}\text { Juniors sitting in consulting with registrar or intern, } \\
\text { and/or parallel consulting. }\end{array}$ & $\begin{array}{l}\text { Johnson et al. (2003); Harris (2009); Nagel et al. } \\
\text { (2011); Williams and Amiel (2012); Silberberg } \\
\text { et al. (2013); Kirby et al. (2014); Kleinitz et al. } \\
\text { (2014); Morrison et al. (2014); Thomson et al. } \\
\text { (2014); Brown et al. (2015); van de Mortel } \\
\text { et al. (2016) }\end{array}$ \\
\hline & Teaching practical skills & Nagel et al. (2011) \\
\hline & Taking student on home visits & Williams and Amiel (2012) \\
\hline Supernumerary GP & $\begin{array}{l}\text { Supervisor oversees several learners consulting } \\
\text { while not personally consulting }\end{array}$ & $\begin{array}{l}\text { Morrison et al. (2014); Thomson et al. (2014); } \\
\text { Brown et al. (2015) }\end{array}$ \\
\hline \multirow[t]{4}{*}{ Shared group teaching: } & Run by GP Teachers & $\begin{array}{l}\text { Harris (2009); Ahern et al. (2013); van de Mortel } \\
\text { et al. (2013); Morrison et al. (2014); Brown } \\
\text { et al. (2015) }\end{array}$ \\
\hline & Run by learners & $\begin{array}{l}\text { Harris (2009); Nagel et al. (2011); van de Mortel } \\
\quad \text { et al. (2016) }\end{array}$ \\
\hline & $\begin{array}{l}\text { All participants given opportunity to present and } \\
\text { lead discussion }\end{array}$ & Thomson et al. (2014) \\
\hline & $\begin{array}{l}\text { Education sessions shared between geographically } \\
\text { located practices }\end{array}$ & Ahern et al. (2013) \\
\hline \multirow[t]{2}{*}{$1-1$ tutorial teaching } & Formal teaching of clinical skills & Williams and Amiel (2012) \\
\hline & Type not stated & $\begin{array}{l}\text { Harris (2009); Nagel et al. (2011); Ahern et al. } \\
\text { (2013); Brown et al. (2015) }\end{array}$ \\
\hline Informal teaching (e.g. tearoom and corridor) & $\begin{array}{l}\text { Discussion of patient cases, broad medical issues, } \\
\text { and careers }\end{array}$ & $\begin{array}{l}\text { Harris (2009); Thomson et al. (2014); Brown } \\
\text { et al. (2015) }\end{array}$ \\
\hline Practice meetings & Learners attend practice meetings & Harris (2009); van de Mortel et al. (2014) \\
\hline Presentations for practice clinical meetings & Learners present at practice clinical meetings & $\begin{array}{l}\text { Harris (2009); Nagel et al. (2011); Silberberg } \\
\text { et al. (2013) }\end{array}$ \\
\hline Interdisciplinary teaching & $\begin{array}{l}\text { Both direct clinical teaching and group tutorials - } \\
\text { view different styles of consulting, learn from } \\
\text { clinicians with varying interests }\end{array}$ & Harris (2009); Thomson et al. (2014) \\
\hline Development of resources for others to present & $\begin{array}{l}\text { Medical students develop resources for others } \\
\text { to present }\end{array}$ & van de Mortel et al. (2016) \\
\hline
\end{tabular}

(teachers who are also formally learning on a training pathway - see Supplementary Appendix 1 Glossary of terms), supervisors and practices, are detailed in Tables 3 and 4. It is noted that benefits for some participants were challenges for others.

The key facilitators for MLL are shown in Table 5 .

\section{Realist synthesis}

The key identified contexts (C), mechanisms (M), and outcomes $(\mathrm{O})$ supporting our hypotheses informing this realist review are discussed in the narrative below and summarized in Supplementary Appendix 6 - contexts, mechanisms, and outcomes. The articles included in this review did not adopt a realist approach to the analysis of their findings and mainly provided self-reported outcome data, with "enhanced learning" being a predominant learning outcome theme. We identified eight key mechanisms that lend support to five hypotheses. The first mechanism, a strong teaching and learning culture, was widely represented throughout the papers, and was considered a context for most other key mechanisms. One additional possible mechanism "learning from practice" provides limited support for our sixth hypothesis.

\section{Hypothesis 1: MLL is facilitated by a range of approaches including methods and experiences.}

Five key mechanisms were identified that support this hypothesis: a strong teaching and learning culture; a learning community; provision of flexible learner-centered education; exposure to a range of teachers and learners using diverse teaching and learning methods; and practice self- determination of appropriate teaching methods and approaches (i.e. not externally defined).

\section{Mechanism 1: A strong teaching and learning culture}

Facilitating and sustaining a teaching and learning culture is crucial in well-functioning MLL practices because it promotes a positive learning environment (O) (Harris 2009; van de Mortel et al. 2013; Brown et al. 2015) and facilitates GP teacher satisfaction (O) (Morrison et al. 2014; Thomson et al. 2014). Practice leaders who are enthusiastic and committed to education and training (C) (Harris 2009; van de Mortel et al. 2013; Kirby et al. 2014; Thomson et al. 2014; van de Mortel et al. 2014) contribute to the development and sustainability of a strong teaching and learning culture. The practice business plan may contain reference to the learning culture (Harris 2009) and the practice needs to ensure the provision of appropriate facilities (such as sufficient consulting rooms, a tea room and meeting room, technology and online resources) (C) (Harris 2009; van de Mortel et al. 2013, 2014, 2016; Morrison et al. 2014; Thomson et al. 2014; Brown et al. 2015). External funding can assist with this (Thomson et al. 2014; Brown et al. 2015). It is important that practice staff are supportive of MLL (Harris 2009; van de Mortel et al. 2013, 2014, 2016) and receive appropriate training for their designated teaching administration roles (C) (Brown et al. 2015). A staff member may be delegated or employed specifically to organize teaching (C) (Harris 2009; Brown et al. 2015) as it is helpful if teaching sessions are planned and appropriately scheduled (Williams and Amiel 2012; van de Mortel et al. 2013; Thomson et al. 2014; Brown et al. 2015). Consideration of financial arrangements for learner-teachers 
Table 3. Key benefits of multi-level learning for learners, learner-teachers, supervisors, and practices.

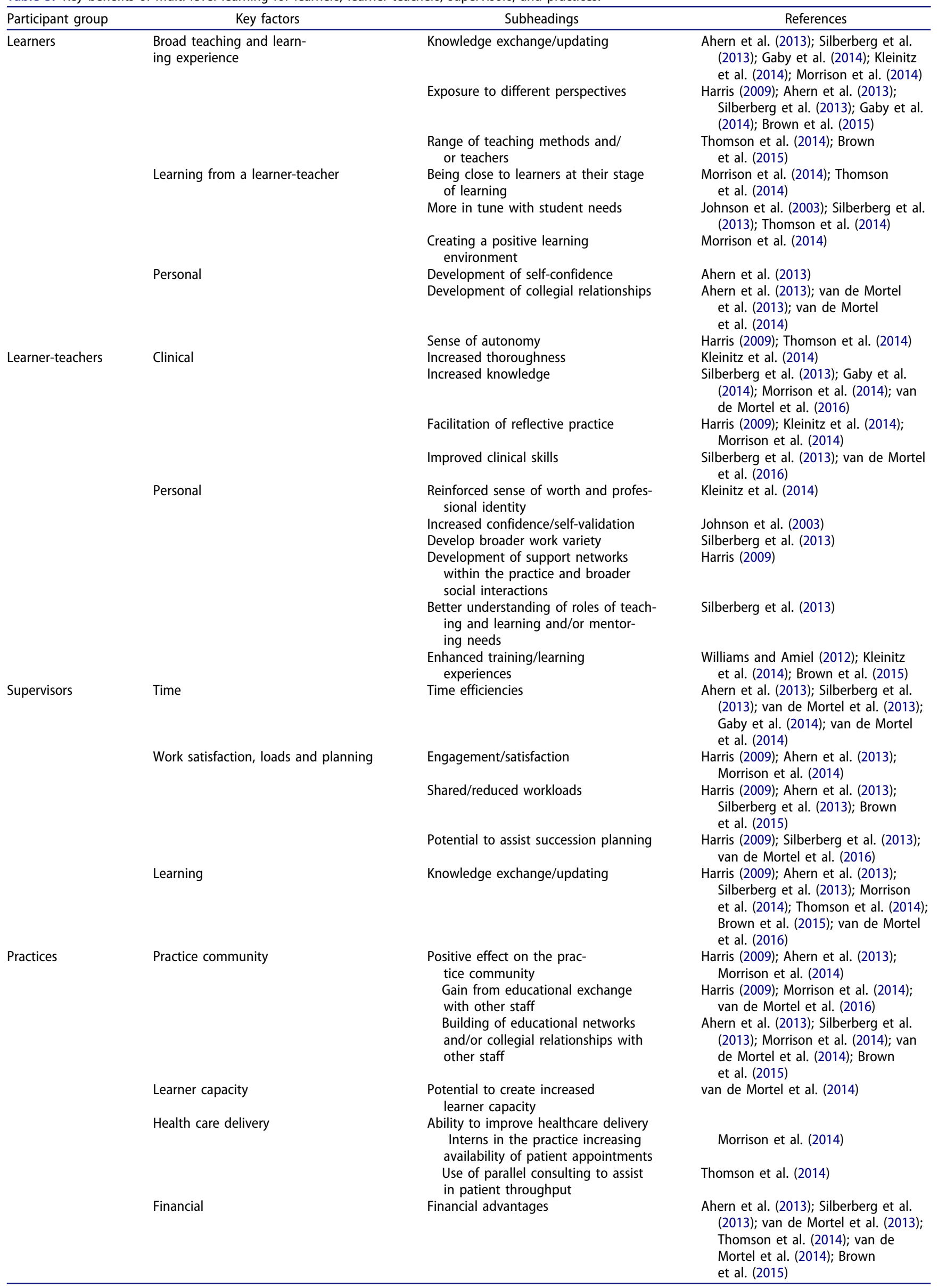


Table 4. Key Disadvantages/challenges for multi-level learning for learners, learner-teachers, supervisors, and practices.

\begin{tabular}{|c|c|c|c|}
\hline Participant group & Key factors & Subheadings & References \\
\hline \multirow[t]{9}{*}{ Learners } & Educational & $\begin{array}{l}\text { Different individual and group } \\
\text { learner needs }\end{array}$ & $\begin{array}{l}\text { Ahern et al. (2013); van de Mortel } \\
\text { et al. (2013); Gaby et al. (2014); } \\
\text { Thomson et al. (2014) }\end{array}$ \\
\hline & & $\begin{array}{l}\text { Different learning levels of group } \\
\text { members/pitching the teaching at } \\
\text { the right level }\end{array}$ & $\begin{array}{l}\text { Ahern et al. (2013); van de Mortel } \\
\text { et al. (2013); Gaby et al. (2014); } \\
\text { Thomson et al. (2014) }\end{array}$ \\
\hline & & $\begin{array}{l}\text { Personal and personality issues } \\
\text { of learners }\end{array}$ & $\begin{array}{l}\text { Ahern et al. (2013); Gaby et al. (2014); } \\
\text { Thomson et al. (2014) }\end{array}$ \\
\hline & & Group dynamics & Ahern et al. (2013) \\
\hline & & $\begin{array}{l}\text { Method of teaching: One-to-one learn- } \\
\text { ing is: }\end{array}$ & \\
\hline & & $\begin{array}{l}\text { more suitable for some learners } \\
\text { and in some situations; }\end{array}$ & Ahern et al. (2013); Gaby et al. (2014) \\
\hline & & $\begin{array}{l}\text { provided concurrently with } \\
\text { shared learning }\end{array}$ & $\begin{array}{l}\text { Ahern et al. (2013); van de Mortel } \\
\text { et al. (2013) }\end{array}$ \\
\hline & & $\begin{array}{l}\text { Variability of teaching skills and effect } \\
\text { on quality of learning }\end{array}$ & $\begin{array}{l}\text { Ahern et al. (2013); Thomson } \\
\text { et al. (2014) }\end{array}$ \\
\hline & Organizational & Scheduling challenges & $\begin{array}{l}\text { Gaby et al. (2014); Thomson } \\
\text { et al. (2014) }\end{array}$ \\
\hline \multirow[t]{8}{*}{ Learner-teachers } & Teaching support and opportunity & Scheduling challenges & $\begin{array}{l}\text { Johnson et al. (2003); Kleinitz } \\
\text { et al. (2014) }\end{array}$ \\
\hline & & $\begin{array}{l}\text { Variable opportunities for learners } \\
\text { to teach: }\end{array}$ & \\
\hline & & $\begin{array}{l}\text { Insufficient space or access to } \\
\text { supervisors }\end{array}$ & $\begin{array}{l}\text { Kirby et al. (2014); Kleinitz et al. } \\
\text { (2014); Morrison et al. (2014); } \\
\text { Brown et al. (2015) }\end{array}$ \\
\hline & & $\begin{array}{l}\text { Lack of expectation for learners } \\
\text { to teach }\end{array}$ & Silberberg et al. (2013) \\
\hline & & $\begin{array}{l}\text { Supervisor concerns about learner } \\
\text { teaching ability }\end{array}$ & Silberberg et al. (2013) \\
\hline & & $\begin{array}{l}\text { Practice resistance toward regis- } \\
\text { trar teaching }\end{array}$ & Johnson et al. (2003) \\
\hline & Clinical & $\begin{array}{l}\text { Time management issues and associ- } \\
\text { ated stress }\end{array}$ & $\begin{array}{l}\text { Johnson et al. (2003); Kleinitz } \\
\text { et al. (2014) }\end{array}$ \\
\hline & Financial & $\begin{array}{l}\text { Lack of remuneration to cover the } \\
\text { effect of teaching }\end{array}$ & $\begin{array}{l}\text { Silberberg et al. (2013); Kleinitz } \\
\text { et al. (2014) }\end{array}$ \\
\hline \multirow[t]{10}{*}{ Supervisors } & Time & Time pressures & Ahern et al. (2013); Gaby et al. (2014) \\
\hline & & $\begin{array}{l}\text { Parallel consulting can be } \\
\text { time-consuming }\end{array}$ & Thomson et al. (2014) \\
\hline & Workload & Workload may be increased & Johnson et al. (2003) \\
\hline & & Disparate learner needs & Morrison et al. (2014) \\
\hline & & $\begin{array}{l}\text { Differing lengths of } \\
\text { learner placements }\end{array}$ & $\begin{array}{l}\text { van de Mortel et al. (2013); Morrison } \\
\text { et al. (2014) }\end{array}$ \\
\hline & Financial & Financial costs for some & Thomson et al. (2014) \\
\hline & & $\begin{array}{l}\text { Having a consultant GP teacher/ } \\
\text { supernumerary supervisor }\end{array}$ & Thomson et al. (2014) \\
\hline & & $\begin{array}{l}\text { Reduced earnings from consulting } \\
\text { whilst teaching }\end{array}$ & Thomson et al. (2014) \\
\hline & & May influence teaching participation & Thomson et al. (2014) \\
\hline & & Poor incentives & Johnson et al. (2003) \\
\hline \multirow[t]{4}{*}{ Practices } & Administration & $\begin{array}{l}\text { Additional workload due to: } \\
\text { Different needs for each }\end{array}$ & \\
\hline & & learner group; & Morrison et al. (2014) \\
\hline & & $\begin{array}{l}\text { Varying learner turnover } \\
\text { time periods }\end{array}$ & $\begin{array}{l}\text { van de Mortel et al. (2013); Morrison } \\
\text { et al. (2014) }\end{array}$ \\
\hline & Infrastructure & Need for increased practice rooms & $\begin{array}{l}\text { Kleinitz et al. (2014); Morrison } \\
\text { et al. (2014) }\end{array}$ \\
\hline
\end{tabular}

(Silberberg et al. 2013; Kleinitz et al. 2014) and GP teachers (C) (Harris 2009; van de Mortel et al. 2013; Thomson et al. 2014; Brown et al. 2015), being aware of the medico-legal indemnity issues for teaching and supervising (C) (Harris 2009), and educational institution communication and support (Brown et al. 2015) may also help to improve the teaching culture. Patients who are accepting of learners (C) (Brown et al. 2015) are crucial to the teaching culture.

Additionally, it is essential to create a safe learning environment by valuing the inputs of all practice members and learners (C) (Harris 2009; Thomson et al. 2014) and to create trust that permits all learners to interact comfortably (Harris 2009; van de Mortel et al. 2013; Morrison et al. 2014). Practice ownership by GPs may positively influence the development of this culture (C) (Thomson et al. 2014).

\section{Mechanism 2: A learning community}

MLL practices enhance learning $(\mathrm{O})$ by creating a sense of community (M) (Morrison et al. 2014). Working and learning relationships are developed (O) through MLL 
Table 5. Key facilitators for successful multi-level learning.

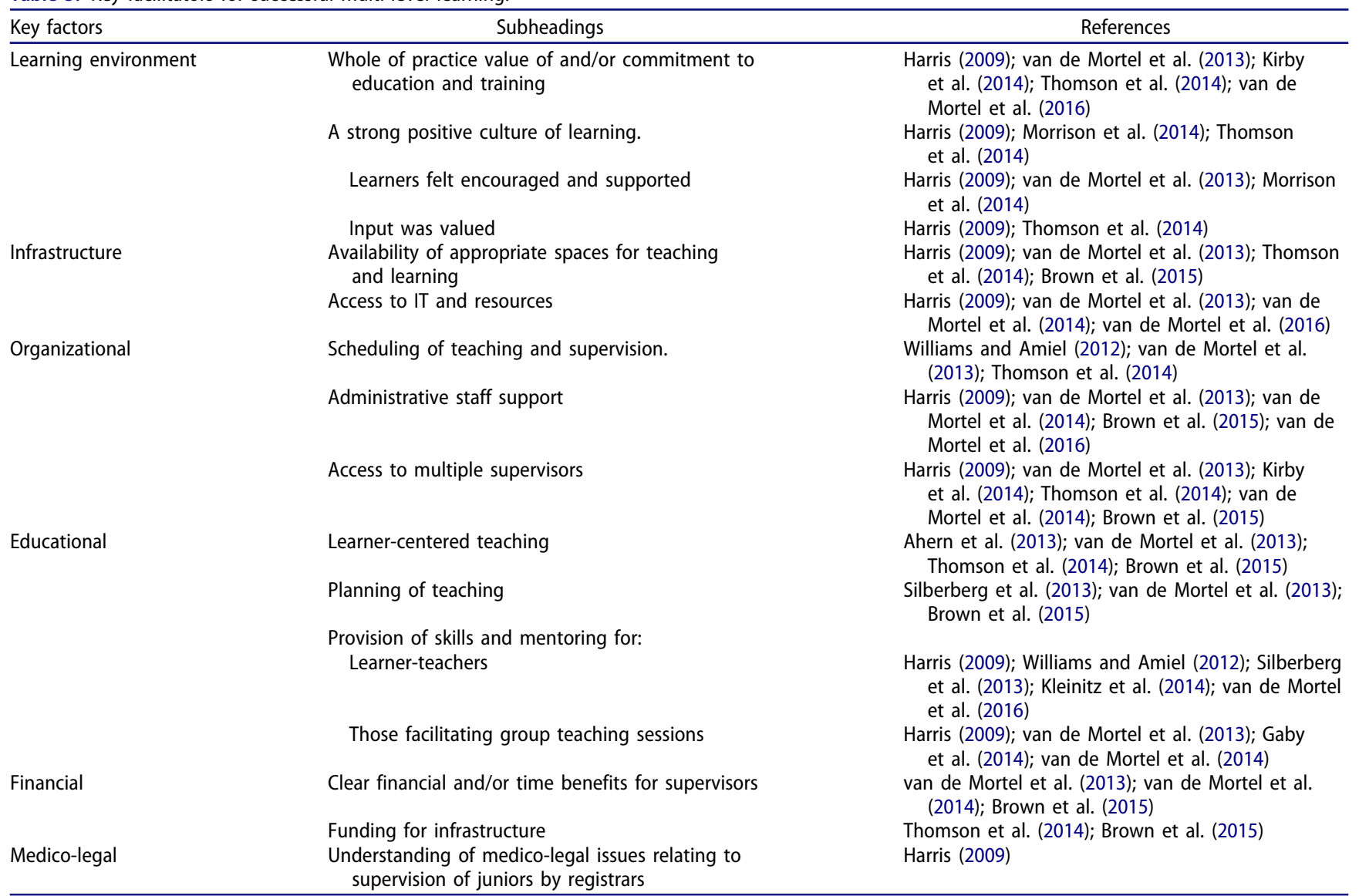

approaches (Harris 2009; Ahern et al. 2013; van de Mortel et al. 2013; Morrison et al. 2014) and learners perceive that there is an equal learning partnership (C) with all groups learning, including senior doctors (Harris 2009; Thomson et al. 2014). Once a practice has a group of learners, they create their own social (Harris 2009; Brown et al. 2015) and educational networks (Brown et al. 2015). Enjoyment of interpersonal relationships is important to learner-teachers (C) (Johnson et al. 2003). The learning community works when practices allow regular opportunities for interaction (C) (Harris 2009). A strong sense of community is important in rural areas, so practices often organize orientation, social functions, and/or accommodation for their learners (C) (Harris 2009; Morrison et al. 2014).

\section{Mechanism 3: Flexible learner-centered teaching}

The ability of the GP to respond to individual learners' needs is important (C) (Ahern et al. 2013; van de Mortel et al. 2013; 2014; Thomson et al. 2014; Brown et al. 2015) to enhance learning experiences (O). This is helped by GP teachers getting to know the learner and/or learner-teacher capabilities (C) (van de Mortel et al. 2016), being aware of each learner's curriculum (Brown et al. 2015), and recognizing not all learners are suitable for all MLL activities (C). One-to-one teaching is seen by some as important to address individual learning needs (Ahern et al. 2013; van de Mortel et al. 2013; Gaby et al. 2014) and various learners and GP teachers believe that a mix of learning methods is most effective (Ahern et al. 2013; van de Mortel et al. 2013, 2014). GP teachers need to be skilled to manage the educational and mentoring challenges of a group of learners with differing clinical knowledge, experience, and needs $(C)$ (van de Mortel et al. 2013, 2014; Thomson et al. 2014) and to reevaluate teaching structures and innovate as needed (C) (Thomson et al. 2014).

\section{Mechanism 4: Exposure to a range of teachers and} learners using diverse teaching and learning methods

Exposure to a range of teachers and learners using diverse teaching and learning methods $(M)$ can enhance knowledge exchange for learners and staff $(\mathrm{O})$. Varied personal and clinical experiences, skills, and backgrounds (C) provide different perspectives and currency of knowledge (Harris 2009; Ahern et al. 2013; Silberberg et al. 2013; Gaby et al. 2014; Morrison et al. 2014; Thomson et al. 2014) and can also "stretch" learners (Gaby et al. 2014) by extending their thinking and skills (O). The benefits can extend to practice staff who may learn from increased discussion and interaction (Morrison et al. 2014).

Specific MLL teaching methods provide different learning opportunities (O). For example, parallel consulting can provide learners with opportunities for autonomy in patient care and one-on-one teaching experience (Thomson et al. 2014). Shared educational sessions such as MLL tutorials can provide opportunities for equal partnerships in learning (O) (Harris 2009; Thomson et al. 2014), a supportive learning environment $(\mathrm{O})$, and the opportunity to revise and update knowledge (O) (Harris 2009; Ahern et al. 2013; Silberberg et al. 2013; Gaby et al. 2014; Morrison et al. 2014; Thomson et al. 2014; Brown et al. 2015; van de Mortel et al. 2016). "Supernumerary GPs" (GPs who are not seeing any/many of their own clinical patients during the time they are supervising and teaching) (C) provide learners with timely access to an experienced GP (Thomson 
et al. 2014), and the interdisciplinary team approach can allow different clinical perspectives (Thomson et al. 2014) (the latter involving teaching by diverse health care professional groups).

Coordinated scheduling of practice and external learning activities (C) is important (Williams and Amiel 2012; van de Mortel et al. 2013; Thomson et al. 2014) and will allow all learners to attend practice teaching sessions (Johnson et al. 2003; Gaby et al. 2014; Kleinitz et al. 2014; Thomson et al. 2014).

The availability of several educators to teach (van de Mortel et al. 2014; Brown et al. 2015) can ease the load and provide different viewpoints (Harris 2009; van de Mortel et al. 2013; Thomson et al. 2014). The teachers require good facilitation skills (C) (van de Mortel et al. 2013, 2014; Gaby et al. 2014).

\section{Mechanism 5: Practice self-determination of appropriate teaching methods and approaches}

A range of approaches and teaching methods are used (O) because practices decide which teaching methods are most appropriate for them (M) based on the context of their own practice. New teaching models may be devised to suit learner and practice needs (O) (Thomson et al. 2014).

GP teacher enjoyment of teaching (C) (van de Mortel et al. 2013; Morrison et al. 2014; Thomson et al. 2014) and beliefs about who should teach and how they should teach (C) (van de Mortel et al. 2016) may influence practice decisions regarding teaching methods and approaches. Practice factors such as organizational and/or infrastructure restraints (C) may limit teaching opportunities (Kirby et al. 2014; Kleinitz et al. 2014; Morrison et al. 2014; Brown et al. 2015) and time and/or financial considerations (C) may affect method choice (Gaby et al. 2014; Thomson et al. 2014).

Learner-teacher variables (C) including teaching skill competence and confidence, personality, enjoyment of interpersonal interactions, and/or appreciation of added workload variety, can be an important part of teaching motivation (C) (Johnson et al. 2003; Silberberg et al. 2013). Learners may be invited to teach, volunteer, be expected to teach as part of their role in the practice (van de Mortel et al. 2016), or indeed may not be expected to teach (Silberberg et al. 2013) (C).

Learners need to be accepting of the practice teaching philosophy and enthusiastically engage with the teaching learning models offered (C) (van de Mortel et al. 2013, 2016). Learner numbers for the practice need to be considered because too many (C) can create competition between senior and junior learners for patients and supervisor time (Morrison et al. 2014).

Hypothesis 2: Multi-level teaching and its facilitation between learners in adjacent/nearby levels of learning are effective because of the similar experiences of the learner-teachers and learners.

\section{Mechanism 6: The social and cognitive congruence of learners and learner-teachers.}

Receiving teaching from a learner-teacher at a nearby training level can enhance learning experiences $(\mathrm{O})$ due to similar social and clinical levels of the learner-teachers and learners (Johnson et al. 2003; Silberberg et al. 2013;
Morrison et al. 2014; Thomson et al. 2014). In this context, there were registrars teaching prevocational doctors and medical students, prevocational doctors teaching medical students (C), and shared learning sessions across all these levels (C). Learner-teachers provided different experiences from those provided by GP teachers because of the learner-teachers' proximity to the learners' stage of training (Morrison et al. 2014) and their understanding of the learners' needs (C) (Johnson et al. 2003; Silberberg et al. 2013; Thomson et al. 2014). In some cases, learner-teachers were able to give students more time than GP teachers (Johnson et al. 2003) and willing to let students do more (Johnson et al. 2003). Cognitive congruence increases the comfort of junior learners' interactions (O) (Johnson et al. 2003; Silberberg et al. 2013; Morrison et al. 2014).

From the learner-teacher's point of view, teaching junior learners can positively affect learner-teacher professional identity (Kleinitz et al. 2014) and confidence (Johnson et al. 2003) (O), and contribute to their own learning (O) (Silberberg et al. 2013; Kleinitz et al. 2014; Brown et al. 2015; van de Mortel et al. 2016). Learner-teachers also report increased thoroughness in clinical practice $(\mathrm{O})$ with junior learner observation (Kleinitz et al. 2014) and gaining encouragement from sharing their experiences (Morrison et al. 2014) and from students providing company and professional support (Kleinitz et al. 2014).

Some learner-teachers found teaching difficult because of time management and clinical pressures (C) (Johnson et al. 2003; Kleinitz et al. 2014) while some learners found learner-teachers less likely than GP supervisors to provide "targeted teaching" or as wide a variety of learning experiences (C) (Johnson et al. 2003; Thomson et al. 2014).

\section{Hypothesis 3: MLL approaches can enhance the acquisition of teaching skills by participants.}

\section{Mechanism 7: Learner-teacher training and support}

Learner-teachers can develop/advance their teaching skills (O) through experience (C) (Kirby et al. 2014). This immersion in MLL, in the context of providing skills and mentoring for learner-teachers (C) (Harris 2009; Williams and Amiel 2012; Silberberg et al. 2013; Kleinitz et al. 2014; van de Mortel et al. 2016), can also provide skills transferable to patient care $(\mathrm{O})$ and improve participants' personal understanding of learning $(\mathrm{O})$.

MLL practices may have an expectation (C) that learners will teach (Thomson et al. 2014; van de Mortel et al. 2016), however, this may be difficult to implement as individual capabilities need to be assessed (Silberberg et al. 2013; van de Mortel et al. 2016). Some learners are not confident to teach (C) (Johnson et al. 2003; Silberberg et al. 2013; Kleinitz et al. 2014), become anxious (Morrison et al. 2014) or are not interested (C) (Gaby et al. 2014). Gradually introducing the teaching role can help with appropriate training, feedback, and mentoring (C) (Silberberg et al. 2013; van de Mortel et al. 2016). Providing planning time (C) and encouraging learner-teachers to commence with familiar topics can help their development as teachers (Silberberg et al. 2013). Learner-teachers may need support to manage time (C) (Kleinitz et al. 2014) and realize appropriate boundary setting for teaching and clinical responsibility (C) (Johnson et al. 2003). It is also important to address 
remuneration for learner-teachers when their incomes will be affected (C) (Silberberg et al. 2013; Kleinitz et al. 2014).

There are clear individual benefits for the learner-teacher. Reflecting on one's own practice and knowledge (O) (Harris 2009; Kleinitz et al. 2014; Morrison et al. 2014), gaining skills applicable to clinical work (O) (Silberberg et al. 2013; Gaby et al. 2014; van de Mortel et al. 2016), and developing a better understanding of the roles and challenges in teaching $(\mathrm{O})$ (Silberberg et al. 2013) can enhance clinical skills (O) and personal learning $(\mathrm{O})$ as well as add variety to a busy working day (O) (Silberberg et al. 2013).

\begin{abstract}
Hypothesis 4: MLL approaches facilitate time efficiencies for GP supervisors by sharing the teaching and learning roles amongst learner levels.
\end{abstract}

\begin{abstract}
Hypothesis 5: MLL approaches contribute positively to increase teaching capacity in the community by sharing the teaching and learning load amongst increased numbers of medical learners in the practice.
\end{abstract}

\section{Mechanism 8: Sharing the teaching and clinical loads with learners}

This mechanism can create multiple outcomes for practices, such as time efficiencies (O) (Ahern et al. 2013; Silberberg et al. 2013; van de Mortel et al. 2013, 2014; Gaby et al. 2014) and financial benefits/advantages (O) (Ahern et al. 2013; Silberberg et al. 2013; Thomson et al. 2014; van de Mortel et al. 2014). It may also assist GP succession planning (O) by giving learners teaching skills (Silberberg et al. 2013; Brown et al. 2015; van de Mortel et al. 2016) and enabling future recruitment by providing a supportive vocational pathway (Harris 2009; van de Mortel et al. 2016). GP teacher satisfaction/enjoyment of teaching (O) (Silberberg et al. 2013; Morrison et al. 2014; Thomson et al. 2014) and a reduction in burn out (O) (Ahern et al. 2013; Thomson et al. 2014) through avoidance of repetitive teaching, may also contribute to increased capacity and practice sustainability (O).

However, sharing teaching and clinical loads with learners can have practice administrative and infrastructure challenges (C) (Harris 2009; Kirby et al. 2014; Kleinitz et al. 2014; Morrison et al. 2014; Brown et al. 2015) as well as potential difficulties managing disparate learner needs and rotation (learner placement) lengths and reporting needs (C) (van de Mortel et al. 2013; Morrison et al. 2014), and so may not be suitable for all practices. Some GP teachers find MLL approaches more time consuming (O) (Johnson et al. 2003; Ahern et al. 2013; Gaby et al. 2014; Thomson et al. 2014), and some practices find there are increased associated workloads (O) (Morrison et al. 2014) and possible financial issues (O) (Johnson et al. 2003; Thomson et al. 2014).

\section{Hypothesis 6: MLL fosters enthusiasm for general practice amongst medical students, prevocational doctors, and registrars.}

\section{Mechanism 9: Learning from practice}

An additional possible mechanism, learning from practice, relates to this hypothesis. The context for this proposed mechanism is a positive learning experience from being taught by a registrar, such that the student learns from involvement in the world of the registrar. This can result in the learner-teacher becoming a proximal role model (O) (Johnson et al. 2003) and fostering enthusiasm for general practice (O) (Johnson et al. 2003). However, as only one paper addressed this topic $(57 \%$ of medical students reported an enhanced interest in general practice following their educational interaction with a registrar (Johnson et al. 2003)), the data are considered too limited to draw any firm conclusions.

\section{Discussion}

This review includes 15 papers providing primary evaluation data from individuals and practices that had experienced MLL in the community-based general practice setting. The majority of these papers have been published subsequent to several previous reviews relating to vertical integration or MLL in general practice (Rushforth et al. 2010; GPET 2011; O'Regan et al. 2013; GPSA 2014).

The main findings from (1) the key review questions and (2) the realist synthesis are summarized and discussed below. This is followed by a discussion on (3) the strengths and limitations of the review, and (4) a conclusion summarizing what this review contributes to the medical education literature.

\section{Key findings from the review questions}

A range of MLL methods are being used in general practices including shared tutorials, clinical supervision and parallel consulting, informal discussions and interdisciplinary teaching (Table 2).

Clear benefits were self-reported for learners, learnerteachers, GP supervisors, and practices (Table 3). For learners, these included broad teaching and learning experiences, learning from learner-teachers in adjacent/nearby levels of training, and the development of collegial relationships. Learner-teachers gained clinical and personal benefits, whilst GP supervisors learned from the knowledge exchange that occurred and developed a sense of satisfaction and engagement. Practices gained a sense of community and for some, the ability to take on more learners. Benefits for some supervisors and practices were seen as challenges for others (Tables 3 and 4). These included time efficiencies or increased time requirements, financial benefit or cost, and workload reduction or increase. Additional challenges included difficulties dealing with disparate educational needs of learners at different training levels, group dynamics, scheduling, and financial issues for learner-teachers. One-to-one learning was sometimes considered more suitable for specific learners or situations, or recommended in addition to shared learning methods.

Overall, our findings are consistent with many of the benefits and challenges of MLL suggested in the literature. Proposed benefits include efficiencies for the practice (Glasgow and Trumble 2003; Dick et al. 2007; O'Regan et al. 2013), broadening of the range of learning experiences and teachers (Birks et al. 2004; Dick et al. 2007) including learning from teachers who are closer and possibly more connected to their situation (Glasgow and Trumble 
2003), improved morale and collegiality (Glasgow and Trumble 2003; O'Regan et al. 2013), enhanced teacher enthusiasm and satisfaction (Glasgow and Trumble 2003), the enhancement or acquisition of teaching skills for registrars and GP trainers (Dick et al. 2007), and the capacity to supervise increased learner numbers (Dick et al. 2007). Proposed challenges include limited physical and financial resources, learners' variable prior learning experiences (Glasgow and Trumble 2003), differing commitment and teaching skills of GPs and learner-teachers, and ensuring fair teaching loads and remuneration for non-salaried registrars (Dick et al. 2007).

Some commonality of findings between MLL and nonMLL approaches would be expected from the experience of teaching and learning per se, regardless of the method used. Practices engaging MLL approaches to teaching and learning may also incorporate the traditional one-to-one apprenticeship model of teaching. Bandura's social cognitive theory, a component of which refers to the acquisition of learning via observing the actions and consequences of others (Kaufman and Mann 2014), helps explain the learning that occurs with one-to-one teaching from a GP specialist or other learner-teacher.

As small group learning is a reported MLL approach in our review, it is not surprising that some of our findings are consistent with the benefits of small group learning described elsewhere. One study demonstrates that small group learning amongst GP specialists for continuing professional development is clearly valued as it incorporates personal, social, as well as professional interactions in the learning process (Zaher and Ratnapalan 2012).

Our review findings also show some consistencies with outcomes from MLL teaching approaches in the hospital environment. Group ward rounds and residents-as-teachers are relevant in this context.

In a survey looking at group teaching in clinical rounds, despite approximately half of the internal medicine specialists (attendings) finding it challenging to engage multiple levels of learners concurrently, trainees (learners of multiple levels) reported $86 \%$ of their teaching was useful and appropriate to their level of training (Certain et al. 2011).

Reported benefits of resident-as-teachers include students valuing resident (registrar) teaching (Whittaker et al. 2006), with residents understanding students' needs and being more approachable (Wilson 2007) and "consciously competent" (i.e. able to deconstruct clinical performance on a given task and facilitate learning by communicating the component steps) (Snell 2011). Benefits for residents include increased enthusiasm for teaching (Morrison et al. 2005), enhanced self-efficacy and overall job satisfaction when time and training are provided (Morrison et al. 2005; Thampy et al. 2013), and enjoyment and learning during teaching (Seely et al. 1999). Teaching concerns for residents can include delayed completion of clinical duties (Yedidia et al. 1995), inadequate time for teaching (Seely et al. 1999), and the need for teaching skills training (SanchezMendiola et al. 2010).

Despite our definition of MLL referring to a wider separation in training stage between learner and learner-teacher than in the commonly used "near-peer" definition (Bulte et al. 2007), many of our findings are in keeping with reported benefits of peer and near-peer teaching in the under- and post-graduate settings. One review identified reports of peer and near-peer teaching over a 12-month period, and provided reasons to consider the use of peerteaching, including alleviating faculty teaching burden, providing role models for junior students, enhancing intrinsic motivation, and preparing future physicians for their educator roles (Ten Cate and Durning 2007). A Canadian study found that near-peer teaching by family medicine residents in the ambulatory clinic promoted self-reflection and confidence in the supervising resident (Ince-Cushman et al. 2015).

We see the benefits and disadvantages of MLL approaches in general practice largely concur with those previously proposed and that MLL has features in common with several other teaching approaches. Our review finding of time, cost, and work efficiencies for some GPs, but not for others warrants further research to identify contributing factors.

\section{Key findings from the realist synthesis}

We identified eight key (and one minor) mechanisms and their associated contexts and outcomes (Supplementary Appendix 6). The first mechanism of "a strong teaching and learning culture" had many contributing contexts, and appeared to be an important underlying context for most of the other mechanisms. The importance of a strong teaching and learning culture in a primary care teaching practice is documented in the published literature (Pearson and Lucas 2011).

Other important mechanisms identified as influencing successful MLL were the presence of a learning community, flexible learner-centered teaching, exposure to a range of teachers and learners using diverse teaching and learning methods, social and cognitive congruence of learners and learner-teachers, learner-teacher training and support, sharing the teaching and clinical loads with learners, and practice self-determination of appropriate teaching methods and approaches. The contexts for successful MLL involved a complex group of variables relating to practice leaders and staff, training, organization, facilities, and learner and supervisor traits. The main outcome was selfreported enhanced learning with several specific outcomes defined for each mechanism.

We believe that the mechanisms identified provide support for our proposed hypotheses, noting that the minor mechanism "learning from practice" (generated from one study's findings) provides insufficient evidence to confidently support the hypothesis "MLL fosters enthusiasm for general practice amongst medical students and prevocational doctors." Several of the mechanisms are clearly not exclusively relevant to MLL but reflect mechanisms that would facilitate enhanced teaching and learning outcomes across a range of teaching methods and environments. Four of the mechanisms however, are particularly relevant to MLL teaching approaches in general practice. These mechanisms and/or their underlying concepts are described in educational literature, though may not have been specifically attributed to general practice education.

1. A "learning community" can be broadly defined as "an intentionally created group of students and/or faculty 
who are actively engaged in learning from each other" (Smith et al. 2014). It aligns closely with the learning theory of communities of practice first described by Lave and Wenger (1991).

2. "Sharing the teaching and clinical loads" has been recommended as a strategy to assist the attainment of sufficient and appropriate clinical supervision for medical learners in general practice (Thistlethwaite et al. 2007; Thomson et al. 2011).

3. "Learner-teacher training and support." Initiatives to improve teaching skills for residents are prominent in the education literature (Morrison and Hafler 2000). Potential benefits of "resident-as-teacher" programs include the development and improvement of teaching skills, enhanced self-efficacy, and interest in education as a career focus for residents, and improvement in clinical skills for learners (Ramani et al. 2016). Halestrap and Leeder (2011) report that GP registrars are keen to be teachers in a multi-level environment and wish for further training.

4. "Social and cognitive congruence" can facilitate enhanced learning, and occurs when learner-teachers are closer in age and stage to their learners than specialists (social congruence), and may have improved understanding of learner needs and how to deliver learning at an appropriate level (cognitive congruence) (Lockspeiser et al. 2008).

Theoretical and educational perspectives considered to hold promise for future medical education include situated learning and communities of practice, social cognitive theory, work-based learning, and experiential learning and reflection (Mann 2011). Viewed from these perspectives, Mann proposes three components that can increase the social dimensions of learning: "approaches that maximize participation, that maximize learning from others and that build on natural community processes to ensure both individual and collective learning" (Mann 2011, p. 66). Many of the contexts, mechanisms, and outcomes of MLL identified in this review embody these aspects and provide opportunities for valuable teaching and learning experiences.

\section{Strengths and limitations}

The main strength of this review is that it analyses empirical data from practices and stakeholders with actual rather than proposed MLL experiences. We used strict selection criteria that limited inclusion to studies of communitybased primary care teaching that met our definition of MLL. It was sometimes difficult determining the eligibility of papers due to the intersecting use of the terms vertical integration, peer/near-peer teaching, and MLL, determining whether participants had actual MLL experience, and variations in study goals, research questions, and reporting of results. This was reflected by our exclusion of eight papers following a careful re-assessment prior to quality appraisal and data extraction. Our strict criteria were necessary to address our specific research questions; however, we acknowledge the potential contributions of excluded papers to the understanding of other MLL aspects.

Our quality appraisals of the papers were to some extent subjective, although each paper was independently appraised by two review team members, with a third providing input when necessary. Though the report by Harris (2009) was included based on the relevance of its three case studies, rather than its rigor, its findings were generally consistent with the findings of other studies.

The generalizability of the review findings is limited by the small number of papers identified, the specific settings of the Australian and UK health systems, and the inclusion only of studies of practices already adopting MLL.

The small number of papers identified indicates a paucity of empirical evaluation data available to answer our specific research questions. This may reflect a difficulty by researchers to find time and resources to conduct research that is frequently unfunded. All of the papers in this review came from Australia and the UK, which have similarities in the role and training of GPs within the health system, and increasing pressures to train medical students and prevocational doctors in the community. The inability to find papers from other countries may reflect different roles and models of general practice and training, the inclusion only of papers written in English, and different opportunities and priorities for educational research. The choice by practices to voluntarily adopt MLL teaching approaches may reflect higher levels of commitment to MLL resulting in more positive outcomes than might be expected from lesscommitted practices attempting to adopt MLL approaches.

\section{Conclusions}

The overall impression from this review is that, given appropriate contexts, MLL initiatives in general practice work for most practices and individuals participating in the process and have many benefits. Benefits of MLL over traditional non-MLL teaching approaches may include the broader range of teaching and learning opportunities offered to learners and the potential for time and cost efficiencies for some practices. Despite some factors that may limit the generalizability of the review findings, we believe the findings can help to inform educators and practices considering implementation or enhancement of MLL initiatives in general practice, and potentially in other community-based settings. MLL requires flexibility and innovation to be successful. No one size fits all and each practice needs to work through how it will best fit them.

A need remains to identify measurable outcomes for the influence of MLL initiatives and experiences on factors such as learner confidence and competence, practice teaching capacity, time and financial efficiencies, learner choice of general practice as a career, and practice succession planning.

\section{Acknowledgments}

We would like to acknowledge Lars Erikson, The University of Queensland, UQ Library, Herston Qld 4006, Australia, for his contributions and assistance with the literature searching. Many thanks also to Dr. G. Dodd Denton, Ochsner Clinical School, The University of Queensland, LA, USA, for his contributions to the review in its early stages of development. 


\section{Disclosure statement}

YW received a University of Queensland Summer Research Scholarship as a medical student to work on the preliminary stages of this review.

The authors report no conflicts of interest. The authors alone are responsible for the content and writing of this article.

\section{Notes on contributors}

Marie-Louise Dick, MBBS, FRACGP, MPH, is an Honorary Associate Professor in General Practice at The University of Queensland.

Margaret Henderson, MBBS, FRACGP, GradDip Clin Ed, is a Lecturer in General Practice at The University of Queensland.

Yi Wei, BHSC/MBBS, commenced work on this project as a medical student on a University of Queensland Summer Research Scholarship. She is currently working in Emergency at The Queen Elizabeth II Jubilee Hospital, Brisbane, Australia and will start General Practice vocational training in 2019.

David King, MBBS, FRACGP, MPH, is a Senior Lecturer in Genera Practice at the University of Queensland.

Katrina Anderson, BMed M Th, FRACGP, is an Associate Professor, General Practice at the Australian National University Medical School.

Jill Thistlethwaite, BSc, MBBS, PhD, MMEd, FRCGP, FRACGP, is an Adjunct Professor at University Technology Sydney, Honorary Professor in the School of Education at the University of Queensland, and a medical advisor for NPS Medicine Wise in Australia.

\section{References}

Ahern CM, van de Mortel TF, Silberberg PL, Barling JA, Pit SW. 2013. Vertically integrated shared learning models in general practice: a qualitative study. BMC Fam Pract. 14:144.

Anderson K, Thomson J. 2009. Vertical integration - reducing the load on GP teachers. Aust Fam Physician. 38:907-910.

Association of American Medical Colleges. 2016. How medical education is changing. In: Policy priorities to improve the nation's health from America's medical schools and teaching hospitals. Washington (DC): Association of American Medical Colleges. Chapter 1.1 p. 1-4.

Bensinger LD, Meah YS, Smith LG. 2005. Resident as teacher: the Mount Sinai experience and a review of the literature. Mt Sinai J Med. 72:307-311.

Birks J, Farrell E, Newson A. 2004. Flexible teaching and learning in general practice. Aust Fam Physician. 33:687-689.

British Medical Association. 2017. Doctors' titles: explained. London: British Medical Association.

Broder J. 2013. Record number of med students, but more needed to help physician shortage. Medscape Medical News. [accessed 2018 Jan 21]. http://www.medscape.com/viewarticle/813306.

Brown JB, Morrison T, Bryant M, Kassell L, Nestel D. 2015. A framework for developing rural academic general practices: a qualitative case study in rural Victoria. Rural Remote Health. 15:3072.

Bulte C, Betts A, Garner K, Durning S. 2007. Student teaching: views of student near-peer teachers and learners. Med Teach. 29:583-590.

Busari JO, Scherpbier AJ. 2004. Why residents should teach: a literature review. J Postgrad Med. 50:205-210.

Certain LK, Guarino AJ, Greenwald JL. 2011. Effective multilevel teaching techniques on attending rounds: a pilot survey and systematic review of the literature. Med Teach. 33:e644-e650.

Critical Appraisal Skills Programme. 2018. CASP checklists: CASP qualitative checklist. Oxford: CASP. [accessed 2017 Dec 11]. https://caspuk.net/casp-tools-checklists/.

Dick ML, King DB, Mitchell GK, Kelly GD, Buckley JF, Garside SJ. 2007. Vertical integration in teaching and learning (VITAL): an approach to medical education in general practice. Med J Aust. 187:133-135.

Frank JR, Snell L, Sherbino J, editors. 2015. The draft CanMEDS 2015 physician competency framework - series IV. Ottawa, Canada: The Royal College of Physicians and Surgeons of Canada.

Gaby M, Lyon E, Kilpatrick S. 2014. An examination and evaluation of mental health teaching and learning in "multi-level learner" general practices. Focus Health Professional Educ. 16:83-100.
General Medical Council. 2013. Good medical practice. Manchester (UK): General Medical Council. [accessed 2015 Jun]. https://www. gmc-uk.org/ethical-guidance/ethical-guidance-for-doctors/goodmedical-practice.

[GPET] General Practice Education and Training Ltd. 2011. Literature review on vertical integration. http://www.agpt.com.au/ArticleDoc uments/235/Vertical\%20Integration\%20Literature\%20Review.pdf.aspx.

[GPSA] General Practice Supervisors Australia. 2014. Vertical and horizontal learning integration in general practice. Bendigo, Australia: GPSA.

Glasgow NJ, Trumble S. 2003. Final report on the case studies on vertical integration for the AAAGP/ADGP GPET working party. Canberra, Australia: General Practice Education and Training.

GP Synergy. 2014. Prevocational general practice placement program (PGPPP). GP Synergy. [accessed 2018 Apr 9]. http://gpsynergy.com. au/wp-content/uploads/2014/07/gp-prevocational-general-practiceplacements-program-gp-synergy-brochure.pdf

Halestrap P, Leeder D. 2011. GP registrars as teachers: a survey of their level of involvement and training. Educ Prim Care. 22:310-313.

Harris F. 2009. Vertical integration. Bentley, Western Australia: Western Australia General Practice Education and Training.

Hays R. 2013. Integration in medical education: what do we mean? Educ Prim Care. 4:151-152.

Health Workforce Australia. 2014. Australia's future health workforce doctors. August 2014. Adelaide, Australia: Health Workforce Australia. http://www.health.gov.au/internet/main/publishing.nsf/ Content/F3F2910B39DF55FDCA257D94007862F9/\$File/AFHW\%20\%20Doctors\%20report.pdf

Heyvaert M, Hannes K, Maes B, Onghena P. 2013. Critical appraisal of mixed methods studies. J Mix Methods Res. 7(4):302-327.

Ince-Cushman D, Rudkin T, Rosenberg E. 2015. Supervised near-peer clinical teaching in the ambulatory clinic: an exploratory study of family medicine residents' perspectives. Perspect Med Educ. 4:8-13.

Johnson C, Liaw S-T, McNair R, Poliness E, Trumble S, Tse J. 2003. INTERACT - integrating registrars as clinical teachers: pilot study. A vertical integration strategy. Final report, Dec 2003. Melbourne, Australia: Department of General Practice, University of Melbourne.

Kaufman DM, Mann KV. 2014. Chapter 2, Teaching and learning in medical education: how theory can inform practice. In: Swanwick T, editor. Understanding medical education: evidence, theory and practice. 2nd ed. Chichester, England: John Wiley \& Sons Ltd; p. $7-29$

Kirby J, Rushforth B, Nagel C, Pearson D. 2014. Should GP specialty trainees teach? Contrasting views from GP specialty trainees and their trainers. Educ Prim Care. 25:96-102.

Kleinitz A, Campbell D, Walters L. 2014. General practice registrar perceptions on training medical students. Aust Fam Physician. 43: 64-67.

Lave J, Wenger E. 1991. Situated learning: legitimate peripheral participation. Cambridge: Cambridge University Press.

Lockspeiser TM, O'Sullivan P, Teherani A, Muller J. 2008. Understanding the experience of being taught by peers: the value of social and cognitive congruence. Adv Health Sci Educ Theory Pract. 13:361-372.

Mann KV. 2011. Theoretical perspectives in medical education: past experience and future possibilities. Med Educ. 45:60-68.

Marsden JS. 2006. An insider's view of the American and UK medical systems. Br J Gen Pract. 56:60-62.

Morrison EH, Hafler JP. 2000. Yesterday a learner, today a teacher too: residents as teachers in 2000. Pediatrics. 105:238-241.

Morrison EH, Shapiro JF, Harthill M. 2005. Resident doctors' understanding of their roles as clinical teachers. Med Educ. 39:137-144.

Morrison T, Brown J, Bryant M, Nestel D. 2014. Benefits and challenges of multi-level learner rural general practices -an interview study with learners, staff and patients. BMC Med Educ. 14:234.

Nagel C, Kirby J, Rushforth B, Pearson D. 2011. Foundation programme doctors as teachers. Clin Teach. 8:249-253.

National Institute of Health. 2014. Quality assessment tool for observational cohort and cross-sectional studies. March 2014. [accessed 2017 Dec 11]. https://www.nhlbi.nih.gov/health-topics/study-qualityassessment-tools.

O'Regan A, Culhane A, Dunne C, Griffin M, Meagher D, McGrath D, O'Dwyer P, Cullen W. 2013. Towards vertical integration in general practice education: literature review and discussion paper. Ir J Med Sci. 182:319-324. 
Park S, Khan N, Hampshire M, Knox R, Malpass A, Thomas J, Anagnostelis A, Newman M, Bower P, Rosenthal J, et al. 2015. A BEME systematic review of UK undergraduate medical education in the general practice setting. BEME Guide No 32. Med Teach Early Online. http://informahealthcare.com/doi/pdfplus/10.3109/ 0142159X.2015.1032918.

Pawson R, Greenhalgh T, Harvey G, Walshe K. 2005. Realist review - a new method of systematic review designed for complex policy interventions. J Health Serv Res Policy. 10: 21-34.

Pawson R, Tilley N. 2004. Realist evaluation. [place unknown]. http:// www.communitymatters.com.au/RE_chapter.pdf.

Pawson R, Tilley NJ. 1997. Realistic evaluation. London (UK): Sage.

Pearson D, Lucas B. 2011. What are the key elements of a primary care teaching practice? Educ Prim Care. 22:159-165.

Ramani S, Mann K, Taylor D, Thampy H. 2016. Residents as teachers: near peer learning in clinical work settings: AMEE Guide No. 106 Med Teach. 38:642-655.

Rodrigues J, Sengupta A, Mitchell A, Kane C, Kane C, Maxwell S, Cameron H, Ross M, Ford M. 2009. The southeast Scotland foundation doctor teaching programme - is "near-peer" teaching feasible, efficacious and sustainable on a regional scale? Med Teach. 31: e51-e57.

Rushforth B, Kirby J, Pearson D. 2010. General practice registrars as teachers: a review of the literature. Educ Prim Care. 21:221-229.

Sanchez-Mendiola M, Graue-Wiechers EL, Ruiz-Perez LC, Garcia-Duran R, Durante-Montiel I. 2010. The resident-as-teacher educational challenge: a needs assessment survey at the National Autonomous University of Mexico Faculty of Medicine. BMC Med Educ. 10:17.

Seely AJ, Pelletier MP, Snell LS, Trudel JL. 1999. Do surgical residents rated as better teachers perform better on in-training examinations? Am J Surg. 177:33-37.

Sen Gupta T, Spencer J. 2001. Why not teach where the patients are? Med Educ. 35:714-715.

Silberberg P, Ahern C, van de Mortel TF. 2013. 'Learners as teachers' in general practice: stakeholders' views of the benefits and issues. Educ Prim Care. 24:410-417.

Smith S, Shochet R, Keeley M, Fleming A, Moynahan K. 2014. The growth of learning communities in undergraduate medical education. Acad Med. 89:928-933.

Snell L. 2011. The resident-as-teacher: it's more than just about student learning. J Grad Med Educ. 3:440-441.

Stocks NP, Frank O, Linn AM, Anderson K, Meertens S. 2011. Vertical integration of teaching in Australian general practice-a survey of regional training providers. Med J Aust. 194:S75-S78.

Ten Cate O, Durning S. 2007. Peer teaching in medical education: twelve reasons to move from theory to practice. Med Teach. 29: 591-599.

Thampy H, Agius S, Allery LA. 2013. The motivation to teach as a registrar in general practice. Educ Prim Care. 24:244-250.

[HENSE] The Health and Education National Strategic Exchange. 2012. Review of medical and dental school intakes in England. Commissioned jointly by the Department of Health and the Higher Education Funding Council for England. https://assets.publishing. service.gov.uk/government/uploads/system/uploads/attachment data/file/213236/medical-and-dental-school-intakes.pdf.

[RACGP] The Royal Australian College of General Practitioners. 2011. The Royal Australian College of General Practitioners curriculum for Australian general practice 2011. Melbourne, Australia: The Royal Australian College of General Practitioners. [accessed 2015 Jun 12]. http://curriculum.racgp.org.au/media/13228/racgp2011curriculum. pdf.

[RACGP] The Royal Australian College of General Practitioners. 2018. Vocational training pathway - requirements for fellowship. The Royal Australian College of General Practitioners Ltd. [accessed 2018 Dec 8]. https://www.racgp.org.au/education/registrars/fellowship-pathways/policy-framework/policies/vocational-training-requirements-for-fellowship.

Thistlethwaite JE, Kidd MR, Hudson JN. 2007. General practice: a leading provider of medical student education in the 21 st century? Med J Aust. 187:124-128.

Thomson JS, Anderson K, Haesler E, Barnard A, Glasgow N. 2014. The learner's perspective in GP teaching practices with multi-level learners: a qualitative study. BMC Med Educ. 14:55.

Thomson JS, Anderson KJ, Mara PR, Stevenson AD. 2011. Supervisiongrowing and building a sustainable general practice supervisor system. Med J Aust. 194:S101-S104.

Topping K. 1996. The effectiveness of peer tutoring in further and higher education: a typology and review of the literature. High Educ. 32:321-345.

Topping KJ. 2005. Trends in peer learning. Educ Psychol. 25:631-645.

van de Mortel T, Silberberg P, Ahern C. 2013. Shared learning in general practice - facilitators and barriers. Aust Fam Physician. 42: 147-151.

van de Mortel T, Silberberg P, Ahern C, Pit S. 2014. Stakeholders' views of shared learning models in general practice: a national survey. Aust Fam Physician. 43:633-638.

van de Mortel TF, Silberberg PL, Ahern CM, Pit SW. 2016. Supporting near-peer teaching in general practice: a national survey. BMC Med Educ. 16:143.

Walters L. 2014. Parallel consulting in rural medical education. In: Chater AB, Rourke J, Couper ID, et al. editors. WONCA rural medical education guidebook World Organization of Family Doctors (WONCA): WONCA working party on rural practice. Chapter 4.3.4. p. 1-10. http://www.globalfamilydoctor.com/groups/WorkingParties/ RuralPractice/ruralguidebook.aspx

Whittaker LD Jr, Estes NC, Ash J, Meyer LE. 2006. The value of resident teaching to improve student perceptions of surgery clerkships and surgical career choices. Am J Surg.191:320-324.

Wijnen-Meijer M, ten Cate OT, van der Schaaf M, Borleffs JC. 2010. Vertical integration in medical school: effect on the transition to postgraduate training. Med Educ. 44:272-279.

Williams B, Amiel C. 2012. General practice registrars as teachers: a questionnaire-based evaluation. JRSM Short Rep. 3:14.

Wilson FC. 2007. Teaching by residents. Clin Orthop Relat Res. 454: 247-250

Wong G, Greenhalgh T, Westhorp G, Buckingham J, Pawson R. 2013. RAMESES publication standards: realist syntheses. BMC Med. 11:21.

Wong G, Greenhalgh T, Westhorp G, Pawson R. 2012. Realist methods in medical education research: what are they and what can they contribute? Med Educ. 46:89-96.

World Federation for Medical Education. 1988. The Edinburgh declaration. World conference on medical education of the world federation for medical education; August 7-12, 1988. Edinburgh, Scotland: World Federation for Medical Education.

Yedidia MJ, Schwartz MD, Hirschkorn C, Lipkin M. Jr. 1995. Learners as teachers: the conflicting roles of medical residents. J Gen Intern Med. 10:615-623.

Zaher E, Ratnapalan S. 2012. Practice-based small group learning programs: systematic review. Can Fam Physician. 58:637-642. 